\title{
Designing Tommy and Pokina Educative Language Game Software: a Transnational Popular Culture Project
}

\author{
Ekawati Marhaenny Dukut, \\ ekawati@unika.ac.id \\ English Department, Faculty of Language \& Arts, \\ Soegijapranata Catholic University, Semarang \\ Christine Ayu Wulandari, \\ christine15ayu@gmail.com \\ Information System Department, Game Technology Program, Faculty of \\ Computer Science; Soegijapranata Catholic University, Semarang \\ Thecla Brenda Chandrawati \\ brenda@unika.ac.id \\ Information System Department, Game Technology Program, Faculty of \\ Computer Science; Soegijapranata Catholic University, Semarang
}

\begin{abstract}
Products of popular culture are many. One of those is educative language game software. Not only is a game useful in combating boredom, but a game can increase someone's education capability. The PC (personal computer) a TOEFL-like game software created by the researchers applies the American TOEFL (Test of English as a Foreign Language) as a basis of the game. It has transnational qualities because it integrates some local Indonesian culture into an American based English competence test. Being a transnational product, the game induces creativity for a number of Indonesian-English students to have a global imagination. The popular culture product named Tommy \& Pokina language game software is an educative game produced for $8^{\text {th }}$ grade students studying at Junior High School. In designing the game, the method of symbolic analogy with the use of simple objects becomes the main characteristics of the game. In its visualization, the design process makes use of not only particular graphics, visualization effects, typography and interface; but also a number of other aspects. The aspects include the object's illustrations, viewpoint, composition, and layout in developing the game's visualization. These aspects are found to be valuable in designing the game.
\end{abstract}

Keyword - educative language game, TOEFLlike PC game software, 8 graders, symbolic analogy, visual asset

\section{INTRODUCTION}

The world of gaming is a platform usually popular in digital media. In popular culture studies, video games and any other gaming media is within the study of popular culture that has transnational characteristics. The transnationality follows the condition that a product is made possible because there is an integration of a widely known or globalized product with a local one.

One of such products is a TOEFL-like PC game software that the researchers have created. The software contains exercises that follow the American made IBT (IntegratedBased TOEFL), where there are Listening, Reading, Writing and also Speaking exercises to improve the English language mastery. Unlike the PBT (Paper Based TOEFL) whose questions are often not connecting to each other by themes and can take up around 3 hours to do the whole test, the game to be discussed here, adopts IBT, which is characterized by exercises that are related to each other and is based upon a certain theme.

The basis for creating the game software actually follows on Ref [1]'s understanding that some Indonesians purchase and use of American commodities as a crucial need to build on their self- 
identity. Thus, playing the PC TOEFL-like game is a way of assisting Indonesians to have a more global identity, but also, more importantly is to be more educated.

Unlike the American TOEFL, where exercises are geared for students to learn about the American culture and language expressions, the aim of creating the game, in this case, is for student players to like consuming vegetables. Through playing the game, which only lasts for around 45 minutes, information about what types of vegetables have what kinds of nutrients, vitamins and minerals are learnt. With the knowledge, the researchers predict that not only will there be an increase in English language skills, the students will also want to consume the vegetable learnt from playing the game.

Originating from Indonesia, the researchers also gave the game its innovation by inserting some local Indonesian scenes in it. The reason for doing so is to help Indonesian students who are the main target to quickly adapt with the game and feel comfortable in playing it. At the same time, if non-Indonesians are playing it, then they would learn something from the Indonesian culture.

With the understanding that playing the game can elevate students' knowledge, the educative game therefore, is regarded not only as a past-time but also as a serious game. A serious game can be entertaining, but it also has the main purpose to educate its users, thereby a game can be referred to an educative game [2]. Citing Project Tomorrow, Ref [2] continues to explain that serious games are made to support tomorrow's generations, who are innovators, leaders and engaged citizens of the world. Thus, not only will playing the game produce innovative students, but at the same time, it challenges educators to be creative in a classroom. Citing Pivec \& Pivec, Ref [2] explains that, the tutor is an adviser in the education process. Not only does a tutor provides knowledge, but also contributes his/her skills to the community. Therefore, tutors and learners need to interact and collaborate within the education processes.

This paper shares the creative collaboration of an English language lecturer with a Game Technology lecturer and student. In designing the educative, and yet serious game there are a number of gaming steps to follow, which is based on a game asset development phase. The phase sets up regulations or conceptual ideas of how to play the game. Among those necessary are on how the graphics, visual effects, typography and interface [3].

Similar to other games, there are basically three aspects that need to be attended, i.e. having visualization, audio and play process of a game. In visualization, all graphic elements that are used to create an interaction with the game players must be seen. Audio wise, the game should be supported by elements that make the game real life because sounds stimulate brains to move the motoric body system. Gameplay wise, the game should have an organized story and the game programs are available to play on. These requirements are in accordance to Ref [4]'s belief that an educative game software needs media that provides a range of choices for players to choose from. If these are made available, consequently, the process of interaction or communication becomes clear enough for the players to understand well of what becomes the main message of the game. Designing an educative game is, therefore, not an easy task, and is thus, worthwhile for discussion.

This paper discusses the process of creating a PC TOEFL-like software game, where the main target is Junior High School students. The researchers believe the game is worthwhile. This is because ever since 2013 the English classes have been banned in most Indonesian primary schools, thereby Indonesian students are lacking basic materials to study English. The time 
allocation given for high school level students is also not supportive. Students are only given two meetings per week. In each meeting, the teacher can effectively use 45 minutes because the 15 minutes is usually spent already on the preparation of the class activity. Ref [5] comments that it is a shame, since it is half the quality of English class tome when compared to the previous curriculum. The English classroom is clearly not as important as before. Usually, the English language learning also takes place in a classical classroom with a teacher providing books for students to read and give exercises based on the understanding of the vocabulary used, in addition to questions that are grammatically based. With this kind of situation, as researchers, we are then challenged to create English game softwares that can become a valuable supplementary material to improve the English mastery of students, and at the same time assist English teachers in providing extra opportunities for students to learn English in a joyful way.

\section{REVIEW OF LITERATURE}

Tommy \& Pokina: English Language Game Software is a PC game that uses two vegetable cartoon characters, i.e. a tomato named Tommy, and a pakchoy named Pokina as the major characters of the software. In presenting the characters, they are supported with Indonesian cultural backgrounds and costume accessories. The vegetable characters are created attractively to invite interest for Indonesian students to learn English, in addition to providing an education about the importance of consuming vegetables, and giving respect to the local culture [6].

A game "does not always give the negative impact for the players when managed correctly" [7]. This is kind of condition is usually met when players are playing and educative game. As a game, the educative game has strategies to choose from. In this game, $8^{\text {th }}$ grade students are targeted as players. In playing the game, they are, firstly, asked to choose one of the two menu boxes provided. One menu box contains TOEFL-like exercises based on Tommy the Tomato Actor, and the other menu is based on Pokina the Pakchoy Chef. Upon starting the game, the first thing they do is type in their names and student numbers. After clicking the start menu, players must choose either Tommy or Pokina to do the TOEFL-like Listening exercise.

Upon clicking one of them, players are then given the task of doing the TOEFL-like Listening exercise, followed by Reading, Writing, and lastly Speaking exercise. As a player, a student is recommended to do the exercises in chronological order. The game has been set for students to play the game in order from Listening to Speaking. Information that are received while listening and seeing a video animation is developed with more complex vocabularies and storyline in the Reading section. Next, the Writing section instructs the players to write up about what they have listened, watched and read. Finally, in the Speaking section, the players are asked to report in speech what they have learnt from all of the information already acquired in the previous sections. Consequently, if they play it in a different order, the answers supplied in the game may be less reliable due to factors mentioned above.

Most Indonesian schools rely on the PC for their computer laboratory work. For this reason, in the game software a 3D Unity program is used. This program is a crossplatform game engine that is used to develop either a 2D or 3D video games and simulations for computers. In the game, 3D unity program is employed in making the digital animation video in the Listening section. It is thus, a particularly interesting section to discuss in this paper. Following herewith is the method of making the Listening section. 


\section{METHOD}

Unlike the real TOEFL test for the Listening section where students rely on what they hear from an audio recording, the PC educative game software makes use of visualization, i.e. the digital animation to support the Listening section. Being visual, the game is equipped with a graphic design which can make use of a 2D or 3D form [8]. The game created makes use of the 3D form. The 3D form is known to be more interesting than the 2D graphic design because it is more communicative with the dimensions that rise from the surface.

In general, the creation process and the design production of the game visual asset start with a descriptive specification that is then followed with the visual plan of the object to be shown in the game. One of those is the mapping out or in giving out the directions of the game formation. With regards to this, the design of a game usually has constraint and analogy [9]. Constraint is the graphic design in games that has a specific condition that is used as a reason for a visual design's constraint, which can consist of four conditions, i.e. radical, formal, practical and symbolic constraints. Then, analogy is the similar or different kinds of component that is borne by two or more things in design creation. The creation, in this case, usually consists of four kinds, i.e. the (1) personal, (2) direct, (3) symbolic and (4) fantasy analogy. In making an analogy, there must be a familiar concept called the analog, and the unfamiliar analogy which is referred as the target.

Because one of the purposes of creating the game is to make children want to consume vegetables, out of the four analogies described above, the game prefers to employ the symbolic analogy, which is a method that can identify an object so it may be adapted for something else [9]. For example, in visualizing Pokina, the process starts from

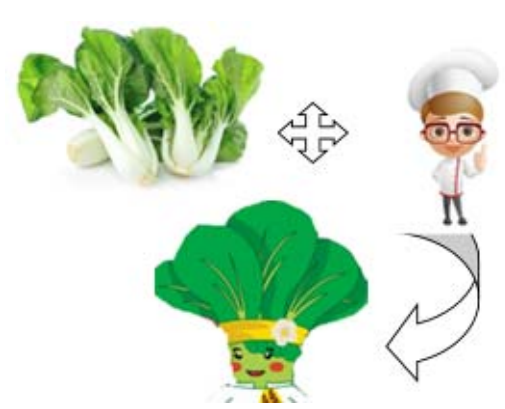

finding an illustration of a real pakchoy vegetable and a cartoon chef to be the model (see Figure 1):

Figure 1. Symbolic analogy of Pokina pakchoy

In Tommy the Tomato Actor, the first thing to do is to find a real tomato as the familiar concept of the symbolic analogy. Then, in creating the unfamiliar concept, which is the target of the analogy, the researchers find inspiration from searching a number of cartoon illustrations of the tomato that has human formations. Since the target is to have a tomato character that looks like an actor, the final step of creating Tommy the tomato actor, is to use imagination to create a cute, lovable cartoon figure which becomes the major character of the TOEFL-like game software (see Figure 2):

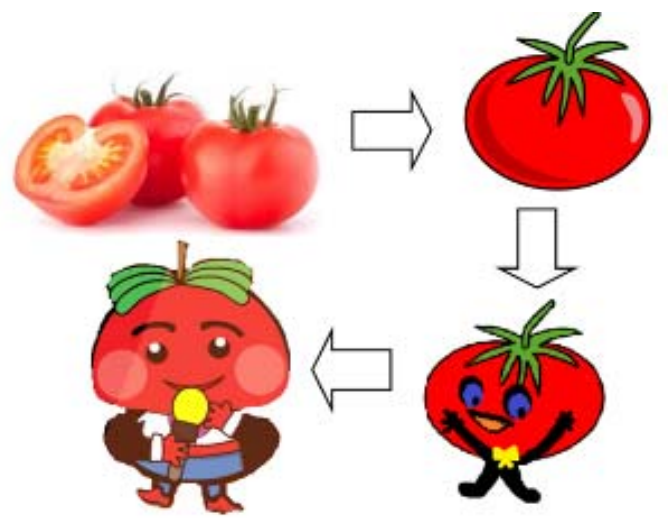

Figure 2. Symbolic analogy of Tommy tomato

In creating the digital animation, the symbolic analogy method is used not only in designing the cartoon characters as visual assets, but also in designing the properties used in a theatre for an actor. 

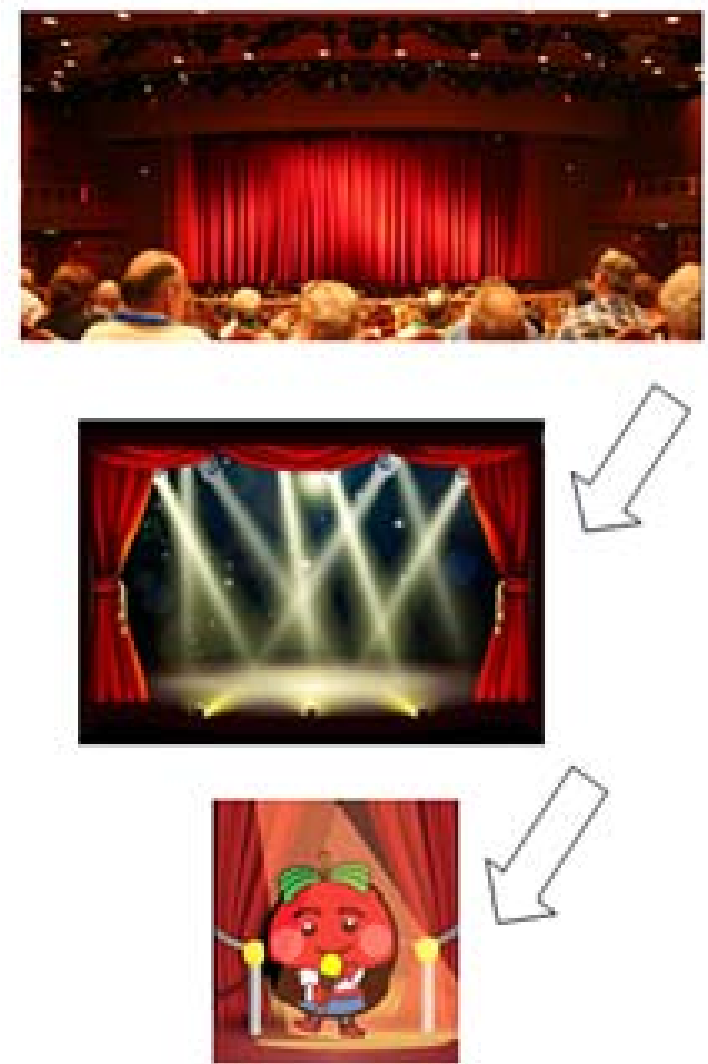

Figure 3. Symbolic analogy of theatre

As can be seen in Figure 3, the first thing to do is to find a real life photo of people seeing in a theatre performance. In this example, the people are seeing a red curtain. Thus, using this as a familiar symbol, it is made analogous with a cartoon picture of a theatre stage. Given an inspiration of a stage with lights and red curtains, therefore, as the next step, Tommy the Tomato Actor is then drawn on a theatre stage. On the stage, Tommy has stage lights on him, and behind him, is a red curtain that will be opened up for him once he is ready to perform as an actor. This similar procedure is likewise done for Pokina's kitchen that has pots and pans hanging on the wall, and a gas stove to cook on, like shown in Figure 4.

The visual asset and parts of the storyline of the digital animation for the Listening section of Tommy \& Pokina: English Language Game Software is a development of the researchers' I Love Vegetable picturebook series like reported in Ref [6].

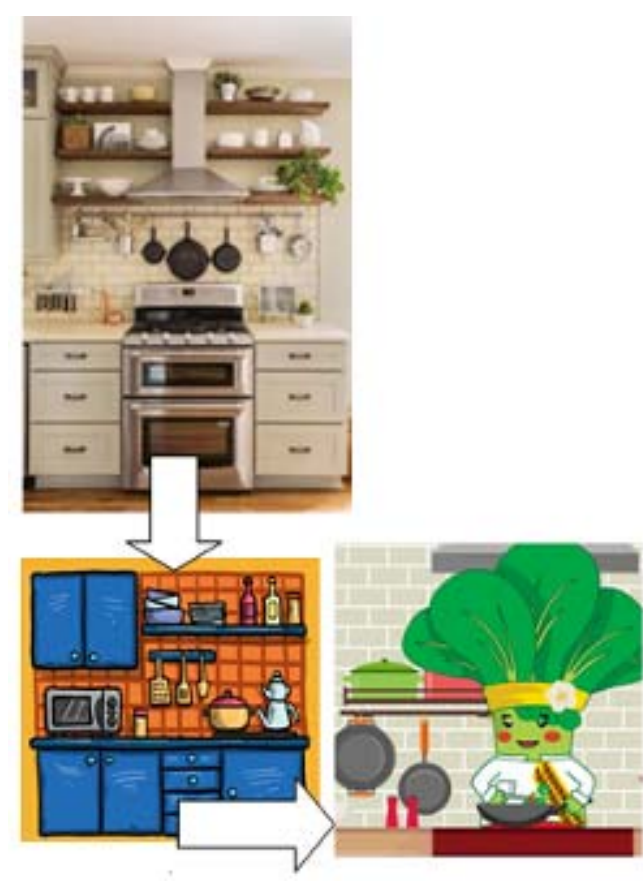

Figure 4. Symbolic analogy of a kitchen

The main idea of transforming some of the information from the picturebooks into a PC game software is none other than the interest of promoting the advantages of vegetable consumption, in addition to helping Indonesian students improve their English language skills in an attractive way. Henceforth, by using symbolic analogy method as informed above, the designing process result of the PC game software is discussed as follows.

\section{RESULT AND DISCUSSION \\ 4.1. Visualization transformation of picturebook to digital animation}

Basically, a book consists of texts and only has few pictures to distribute information. With this kind of situation, it does not attract young readers very well. Young readers are said to be more attracted to products that use a lot of graphics because there are attractive colors, lines, pictures, lettering, space, and photography to be seen. Not only are they effective to transmit visual messages but they can affect the readers aptly. Because of this reason, the researchers have created stories for students of Kindergarten and Elementary School level to 
read in the form of picturebooks. However, to attract more students, who are at a High School level, the story in picturebook form is transformed into a digital animation that is designed for a PC game software.

In designing it, a graphic model with a symbolic analogy method is used to invent a video or digital animation. In the invention, an asset design is produced. The following is a discussion on how the game software is created. First, in visualizing the video, the researchers decide on two out of the five major vegetable characters she has used in her picturebook series. The two characters chosen is Tommy the Tomato Actor and Poki the Pakchoy Chef. These two vegetable characters are chosen for the reason that most students are familiar with how red tomatoes look like, but also for the reason that not many students would know about the pakchoy vegetable.

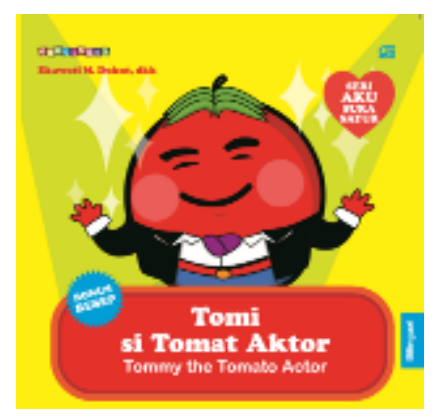

Figure 5. Tommy the Tomato Actor

As can be seen, in Tommy the Tomato Actor figure, the tomato cartoon character is familiar enough with its round red face with green hair representing tomato leaves, and plump body wearing a suit to represent itself as a popular theatre actor. The other picturebook character chosen is Poki the Pak Choy Chef. In the book version, the character is male (see Figure 6).

Because the PC game software should attract both kinds of gender, for the purpose of the digital animation, Poki is then developed into a female character. This is done by giving Poki some girly characteristics. For example, is drawing rosy red cheeks, more noticeable green hair at the forehead with a flower on the right side of a yellow head band, curly eye lashes and larger expressive eyes (see Figure 2).

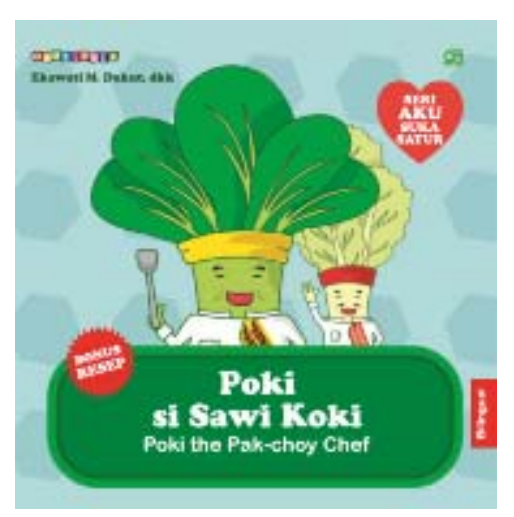

Figure 6. Poki the Pak Choy Chef

In the design process of producing a digital animation, a good storyboard is needed. A storyboard is a sketch of continuous pictures that is organized systematically. The story does not need to detailed and realistic. What it needs is a cinematic background and a visualized idea of what the character must do in the animation. Basically, the objective from the previous Tommy and Pokina picturebook, there is an understanding that the same objectives are delivered in the PC game version. First, the animation should start by telling game players about the vegetable characters that have certain occupations. Second, in describing about themselves, the vegetable character should also inform the kinds food variation that could use the vegetable as the basis of the menu described.

For example, tomatoes and pakchoy are most favorite vegetables used for an Asian stir fried vegetable dish called cap jay. Since, players may wonder how to pronounce the vegetable dish name, the third objective of the game is to have the narrator inform that the beginning sound of the word starts with a sound similar to a popular silent movie actor, named Charlie Chaplin. As the fourth objective, the game also becomes a media to inform what kinds of vitamins and minerals are contained in the vegetables. For example, 
a tomato has high vitamin $\mathrm{C}$ that acts as antioxidant and helps protect body cells from damaging too quickly. Lastly, the fifth criteria, is for the game to show how the vegetables can have innovative recipes, like tomato milk pudding and pakchoy ice cream.

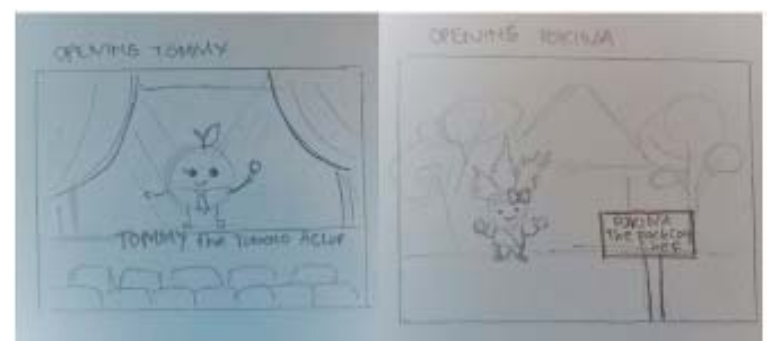

Figure 7. Storyboard Opening Scene for Tommy \& Pokina

The storyboard above is for the opening scene of the two digital animations chosen (see Figure 7). The story board is based on the idea that as an actor, Tommy the tomato should be on stage with a red curtain and flashy stage lights. The opening scene for Pokina, however, informs that pakchoy is a vegetable from a cabbage family. Therefore, in introducing Pokina, the vegetable is seen standing around a field with her relatives, i.e. the white cabbage green choy sum.

\subsection{The creation of digital animation assets}

Nowadays, many kinds of digital technology are available as media for delivering educative stories. One of the advantages of creating a digital animation is having characters that can move and talk, rather than just be still. In making a digital animation as asset of the game software, therefore, the visualization needs to be given attention. One such asset is the choice of colors used in the animation. It should be attractive enough to make players become interested in continually watching the animation. The colors used should also enhance the movements of the characters. The combination of the black and white color should be enough to show the blinking movements of the cartoon character's eyes. A dash of white on the red juicy tomato character, when used appropriately can give it a flashing result. The use of yellow combined with some white, grey or orange background gives the effect of stage lights shining over Tommy the Tomato Actor. Other small combination of colors that accentuates the vegetable cartoon character's movements is in the use of the orange colored tongue. The shape variations of the tongue and mouth are matched up in accordance with the dubber's voice, so as a result, Tommy seems to be talking to the game players.

Tomatoes are good for the skin and can be used as a facial mask. It also helps cure scurvy because of the vitamin $\mathrm{C}$ it contains. Therefore, as an asset the game does not only entertain, but also educate players.

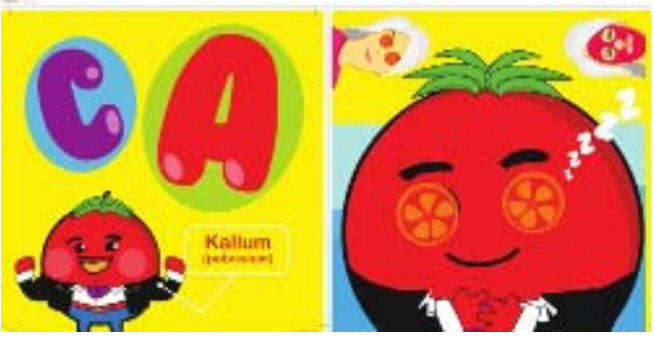

Figure 8. Tommy tomato and his vitamins and minerals

In the cartoon scene, there is Tommy showing the vitamins and mineral a tomato has and how tomatoes can be applied on the face as cream or just have slices of tomatoes on the eyelids (see Figure 8). These interesting assets are made as interesting as possible and have become one of the scenes that help players answer some of the game's Listening and Reading exercises.

Unlike the picturebook form (see Figure 9), the digital animation version does not have a male but rather a female pakchoy character.

Thus, instead of Poki, the character called Pokina is shown cooking in the kitchen (see Figure 10).

To show the different kinds of assets between picturebook form and animation, the 
researchers have shown that the female Pokina has red rouge on her cheeks, a flower accessory on her yellow head band, and a curly green hair fringe on her forehead.

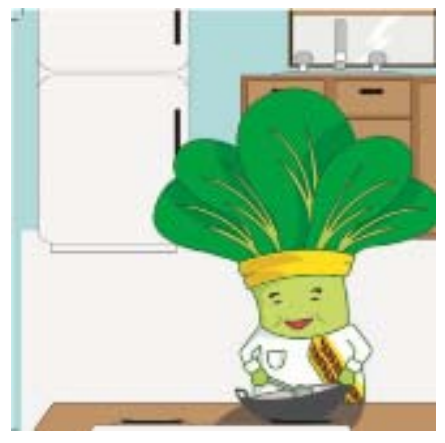

Figure 9. Picturebook Poki

Consequently, in visual terms, there are girly elements to the video animation. Another important asset to distinguish is the more realistic environment Pokina's kitchen has. Unlike the picturebook, which only has a refrigerator, the animation's kitchen has pots and pans hanging on the wall. In the background, rather than having an empty cupboard, there are plates and glasses in it.

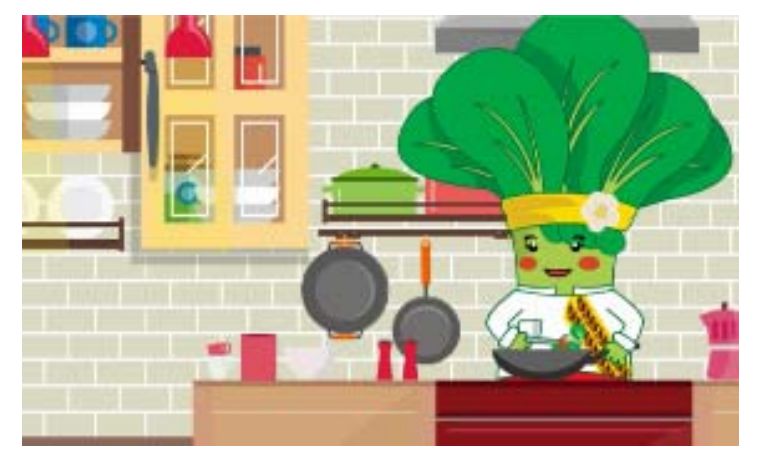

Figure 10. Digital animation Pokina

As can be seen from the background, Pokina is suggestively cooking far more frequently than Poki because she has pots and pans hanging behind her with a cupboard filled with plates and glasses. She also looks younger, thus giving reason why she probably has to work harder as a chef.

It is important to also give attention to both Poki and Pokina's costume. Usually a chef would only wear white costume. However, in both the book and also followed in the digital animation, there is a motif at the right side of the white costume. That motif is a yellow and brown batik motif, which is one of the unique cultural products of Indonesian clothing. This batik pattern is maintained in the animation without any changes, because it is a cultural asset that needs to stay.

Like the costume, there is also another cultural element that is maintained in the animation. It is the local Indonesian bakso, which is a popular street menu usually sold by a seller, who is walking around streets and pushing a cart of clear soup with pakchoy and meatballs made from minced meat. In the digital animation, because sound is an important asset, the game is equipped with a scene that shows the usual habit of the bakso seller. This habit is the clinging sound of a spoon hitting a number of times on a bowl. This kind of local culture scene is one of those, which makes Indonesian students feel comfortable with, although the test is in English.

In the story of Tommy the tomato, a similar strategy is used, i.e. a scene of some applying tomato facial mask shows that some Indonesian people prefers tomatoes to give vitamins and nutrients to brighten their face. It is one of the ways of promoting a habit to the younger Indonesian generation that the Indonesian culture can rely on vegetables rather than factory tablets to make someone healthy. It is in fact this cultural intrusion in the digital animation that makes the game educative and supports the importance of sharing to others what local wisdoms Indonesian people has in store.

After the listening section that makes use of the digital animation, the students as players of the game are asked to read a more academic information on either of the vegetables. Afterwards, the writing and speaking exercise also deal with how the students can report on what they know about the vegetables. With this kind of arrangement, students are then trained to do an integrated TOEFL-like exercise, thereby, 
preparing them for a successful English language learning in the next school level, i.e. in a senior high school and later in a university, too.

\subsection{The compositing of elements}

Compositing is the process in which a film or video production uses multiple images and effects for the image of a single background screen to show that the character is within a single arena. To show movements of the eyes, mouth and hands of the vegetable cartoon, an Adobe Flash/ CC animate program is used. With regards to the sound, the mp4 or avi sound is quipped in the game.

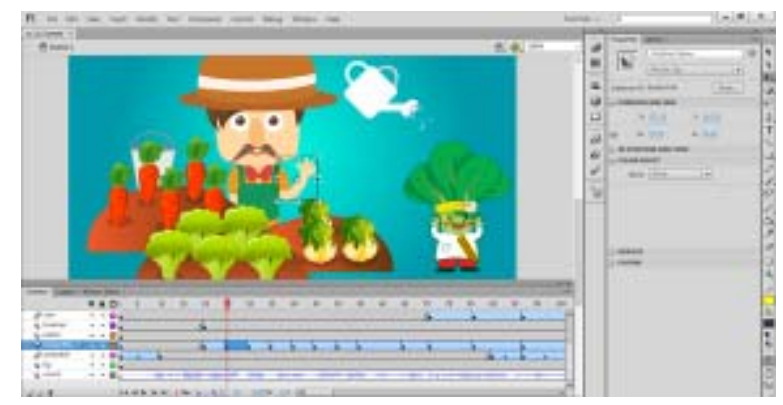

Figure 11. Compositing using Adobe Flash

Out of all the movements to be animated, the moving lips are the hardest to do because it has to match exactly with the dubber's sound. Whenever the speaker says, for example, an "ah" sound, the cartoon character's lips must also be opened to show that it is saying the same vowel sound. Figure 11 shows the compositing process of Pokina's video or digital animation, which uses a single background to feed in the animation movements and sound production.

\subsection{The rendering process}

Rendering is the process in which a video production or digital animation uses multiple images and sound effects for the transition of scenes. In Pokina and Tommy, the video animation uses Adobe Premiere. It is a time-line based video and editing application that enables $2 \mathrm{D}$ graphics turn into a 3D. In doing so, many cartoon scenes or with just some slight differences are used as metadata. These metadata are matched with relevant sounds to be uploaded as the video animation's footage. It is a time consuming process, where every single second counts. Failure of matching the picture scenes and the speech produced by the narrator in the story will make some movements unrealistic. A screen capture of the rendering process is seen in Figure 12.

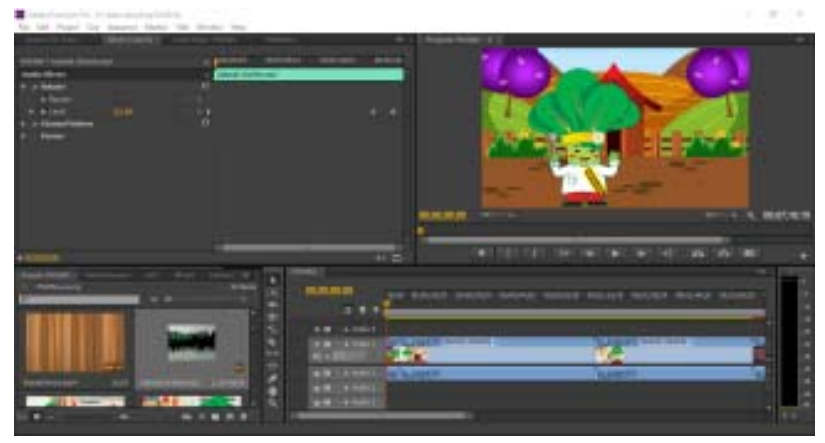

Figure 12. Rendering with Adobe Premiere

\subsection{The asset design supplement}

The supplement of the asset design uses a User Interface (UI) that gives a faceto-face communication from the player with the computer system. The Graphical User Interface (GUI) is the graphics interface that is used for players to use the game by pushing or clicking the media's buttons. The buttons help players do what is needed by the game's system. In Pokina and Tommy's game software the buttons are given bright colors, so they stand out from the brown woody background (see Figure 13).

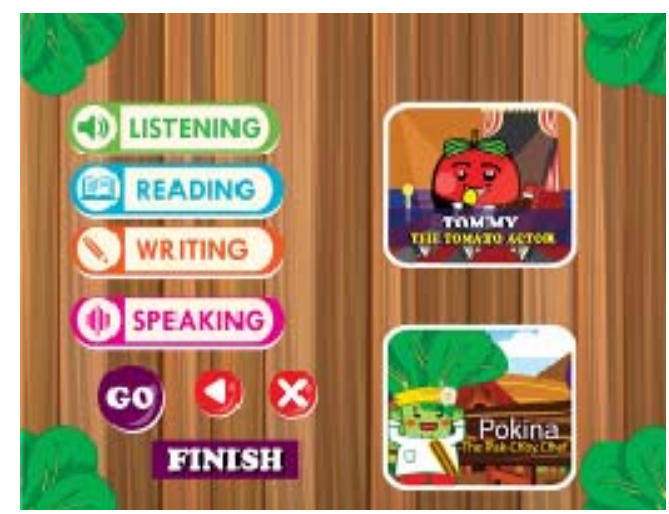

Figure 13. GUI Asset 
In the game, players are given a list of colorful buttons to click on. In the game, players are suggested to chronologically click on the bright green Listening button, before clicking on the bright blue Reading, then bright orange Writing and finally the bright pink Speaking sections. To start it, the players are asked to click on the bright purple GO and end it by clicking the bright purple FINISH button. There is also a red symbol of going back or do a reverse/ undo action, in addition to a cross sign to show that a player does not want to go ahead. More details on how to play the game is discussed in the head researcher's article supplied in Ref [10].

\section{CONCLUSION}

Realizing that the English language curriculum has minimized the frequency of English class meetings, the researchers form the English Department has collaborated with the Information System Department that specializes in Game Technology to produce a TOEFL-like PC language game software named Tommy \& Pokina English Language Game Software. Due to the educating elements it has, the game is classified under a serious educative game. It is targeted for $8^{\text {th }}$ grade students, who already has enough English skills to play with a game where all of the instructions ae in English.

The game is created in that players can integrate all of the information received by going through the Listening, Reading, Writing and Speaking sessions, in order to do the exercises that follow after. The paper discussed in particular, the design process of the digital animation. Starting with deciding which visual scenes should be developed into a video. Then, digital animation assets need to be created to support the compositing of the digital animation elements. After this, the rendering process and asset design supplements that is using the features of graphical user interface are put in its place to activate the game.
In playing the game, there is a challenge of making sure that the buttons to click on will show players what to do next. This will ensure that at the end all work can be saved for the game operator and English teacher see a report of how well the Indonesian English students have answered the questions.

In watching and listening to the animation of either Pokina the Pak Choy chef or Tommy the Tomato Actor, students can learn about the nutrients of the vegetables discussed in addition to knowing what kinds of recipes can be prepared from those vegetables.

This game is unique in that some Indonesian cultural elements are integrated in the game. Among those are the scenes about an Indonesian bakso seller in the pakchoy vegetable story, and the tomato used as facial mask in the story about Tommy the Tomato Actor. These local scenes are the reason for the transnational quality of the educative game software as a product of popular culture. Thus, in playing the TOEFL-like PC game software, not only do Indonesian English students improve their language ability, they also improve their understanding of their own local culture.

\section{ACKNOWLEDGEMENT}

The researchers, Ekawati and Brenda, as writers of this manuscript especially thank the Ministry of Research, Technology and Higher Education in Indonesia (Kemenristek Dikti contract no. 011/K6/KM/SP2H/PENELI-TIAN/2017) for the monetary support of carrying on this research this PPT (Penelitian Produk Terapan) scheme, with the title "Model Pembelajaran Bahasa Inggris Interaktif dengan Cergam Animasi Berbasis Budaya”. A special thanks also goes to Beasiswa Unggulan committee who has provided Christine with a scholarship for her undergraduate studies. 


\section{REFERENCES}

[1] E. M. Dukut, “A Popular Culture Research on American Hegemony in Transnational Women Magazine Advertisements," Rubikon: Journal of Transnational American Studies, vol. 2, no. 1, pp. 64-82, 2015. Available: DOI:http://repository.unika.ac.id/15539/ 1/Eka.Rubikon\%20vol\%202\%20no\%20 1.pdf [Accessed: 20-July-2017].

[2] P.-M. Noemí and S. H. Máximo, "Educational games for learning," Universal Journal of Educational Research, vol. 2, no. 3, pp. 230-238, $2014 . \quad$ Available: DOI: 10.13189/ujer.2014.020305.

[3] W. Wibawanto, "Pengembangan Aset Visual dalam Game Simulasi Pertanian Organik 'Astro Farmer' dengan Pendekatan Symbolic Analogy,” Imajinasi: Jurnal Seni, vol. IX, no.1, 2015. Available: https://journal.unnes.ac.id/nju/index.php/ imajinasi/article/view/8854 [Accessed: 20-July-2017].

[4] W. Wibisono and L. Yulianto, "Perancangan Game Edukasi Untuk Media Pembelajaran Pada Sekolah Menengah Pertama Persatuan Guru Republik Indonesia Gondang Kecamatan Nawangan Kabupaten Pacitan," $J$. Speed-Sentra Penelit. Edukasi, vol. 2, no. 2, pp. 37-42, 2010. Available: DOI: http://dx.doi.org/10.3112/speed.v2i2.878 [Accessed: 20-June-2017].

[5] H. I. Augustien, “The 2013 English Curriculum: the Paradigm, Interpretation, and Implementation," Recent Issues in English Language Education: Challenges and Directions, pp. 39-64, 2014.

[6] E. M. Dukut, M. P. Utami, A. Nugroho, N. I. Putri, and P. Y. Nugrahedi, "Using Popular Cultures Media of Indonesian English Picturebooks as a Way of
Reaching More Vegetable Consuming Children,” A Journal of Culture, English Language Teaching \& Literature., vol. 14, no. 1, pp. 36-47, 2014. Available: DOI:https://doi.org/10.24167/celt.v14i1. 55 [Accessed: 20-July-2017].

[7] C. A. Wulandari, “ “ Wisata Budaya Jawa Tengah ' Game as a Means of Preserving the Culture of Central Java," SISFORMA, vol. 4, no. 2, pp. 28-33, 2017. Available: DOI:10.24167/sisforma.v4i2.1171.

[8] N. Yanti, R. Sanjaya, and F. H. Prasetya, "Graphic Design of ' Green Mission' Education,” SISFORMA, vol. 4, no. 2, pp. 1-6. Available: DOI:10.24167/sisforma.v4i2.1297.

[9] W. Wibawanto, "Pengembangan Aset Visual dalam Game Simulasi Pertanian Organik 'Astro Farmer' dengan Pendekatan Symbolic Analogy," Imajinasi: Jurnal Seni, vol. IX, no.1, 2015. Available: https://journal.unnes.ac.id/nju/index.php/ imajinasi/article/view/8854 [Accessed: 20-July-2017].

[10]E. M. Dukut, "Popularizing Indonesian scenes through picturebooks and digital animation software: a World Englishes teaching idea,” Asian Englishes, 2018. Available:

DOI:10.1080/13488678.2018.14590 